\title{
Comparison of urethral sling surgery and non-ablative vaginal Erbium:YAG laser treatment in 327 patients with stress urinary incontinence: a case-matching analysis
}

\author{
Nobuo Okui ${ }^{1,2,3,4,5}$ (D) Hironari Miyazaki ${ }^{2,6} \cdot$ Wataru Takahashi ${ }^{2,7,8} \cdot$ Toshihide Miyauchi $^{2,9} \cdot$ Chikako Ito $^{2,10}$. \\ Machiko Okui ${ }^{2,5} \cdot$ Kaori Shigemori $^{6} \cdot$ Yoshiharu Miyazaki $^{6} \cdot$ Zdenko Vizintin $^{11}$ (D) $\cdot$ Matjaž Lukac $^{11}$ (D)
}

Received: 13 October 2020 / Accepted: 5 April 2021 / Published online: 22 April 2021

(C) The Author(s) 2021

\begin{abstract}
Stress urinary incontinence (SUI) occurs when abdominal pressure, such as from coughing or sneezing, causes urine leakage. We retrospectively compared tension-free vaginal tape (TVT) and non-ablative vaginal Erbium:YAG laser treatment (VEL) by propensity score (PS) analysis in women with SUI. No PS analysis studies have investigated urethral sling surgery using polypropylene TVT and VEL for SUI. Data from patients aged 35-50 years who were treated for SUI and registered at several institutions were selected. Patients with medical records covering 1 year for the 1-h pad test, who completed the International Consultation on Incontinence Questionnaire-Short Form (ICIQ-SF) and the Overactive Bladder Symptom Score (OABSS), were included. We analyzed 102, 113, and 112 patients in the TVT, VEL, and control groups, respectively. Compared with the control group, the TVT and VEL groups exhibited significant improvement in the 1-h pad test and ICIQ-SF. In the PS analysis, the TVT and VEL groups similarly improved in the 1-h pad test and ICIQ-SF. As for the OABSS, the VEL group showed significantly greater improvement than the TVT group. In the odds ratio analysis for the 1-h pad test, no differences in any of the parameters were observed between TVT and VEL. VEL may be considered an alternative to TVT for SUI treatment.
\end{abstract}

Keywords Propensity score analysis $\cdot$ Stress urinary incontinence $\cdot$ Tension-free vaginal tape $\cdot$ Non-ablative vaginal Erbium:YAG laser treatment

Nobuo Okui

okuinobuo@gmail.com

Urology, Kanagawa Dental University, Yokosuka, Kanagawa, Japan

2 Urology, Dr Okui's Urogynecology and Urology,

Yokosuka, Kanagawa, Japan

3 Urology, Teikyo University, Tokyo, Tokyo, Japan

4 Urology, Koshigawa Hospital, Dokkyo University, Saitama, Saitama, Japan

5 Urology, Yokosuka City Hospital, Yokosuka, Kanagawa, Japan

6 Urology, Yakuin Urogenital Clinic, Fukuoka, Fukuoka, Japan

7 Urology, Kengun Kumamoto Urology, Kumamoto, Kumamoto, Japan

8 Urology, Kumamoto University, Kumamoto, Kumamoto, Japan

9 Urology, Ooita Urology Hospital, Ooita, Ooita, Japan

10 Urology and Gynecology, Saint Sofia Clinic, Nagoya, Aichi, Japan

11 Fotona d.o.o., Stegne 7, 1000 Ljubljana, EU, Slovenia

\section{Introduction}

Stress urinary incontinence (SUI) occurs when abdominal pressure such as that from coughing or sneezing causes urine leakage [1]. It affects up to $49 \%$ of all women. Mixed urinary incontinence (MUI) affects up to $29 \%$ of all women [2] and is a combination of SUI and urge incontinence, in which a strong urge to urinate is accompanied by urinary leakage.

SUI is commonly treated with mid-urethral sling surgery using polypropylene mesh tape. Tension-free vaginal tape (TVT) surgery is a typical procedure for SUI. These procedures have shown good treatment outcomes. However, there is a long-term risk of complications due to the artificial nature of the tape [3].

Recently, patient concerns over the implantation of artificial objects [3] have made it necessary to develop new therapies for incontinence. This has led to research on methods for vaginal and urethral irradiation with lasers, including nonablative vaginal Erbium:YAG laser treatment (VEL) [4]. VEL uses an Erbium:YAG laser, which has a 2940-nm 
wavelength absorbed by water. By adjusting the laser's pulse mode, the mucosa can be uniformly heated without heat accumulation on the surface layer $[5,6]$, raising temperatures to $45^{\circ} \mathrm{C}$ deep in the tissue and $67^{\circ} \mathrm{C}$ on the surface. The treatment promotes cellular synthesis by improving collagen remodeling and blood flow, and it has been reported to improve urinary incontinence [7-9].

While a comparison of TVT and VEL would be meaningful, thus far, the literature only includes one prospective study evaluating incontinence only, which was conducted by our research group [10]. In the present study, we retrospectively extracted TVT and VEL cases from the Japanese medical records to establish a database containing all SUI procedures and outcomes. We have named this database the Urinary Incontinence Research Network (UnIcoRN) database, and it was used throughout this study to retrospectively analyze SUI propensity score (PS) [11].

Recent International Consensus Group recommendations suggest that laser therapy should be restricted to research until further robust data are available [12-14]. On July 30, 2018, the United States Food and Drug Administration (FDA) issued a warning against the use of energy-based devices (EBD), including laser, to perform "vaginal rejuvenation" or vaginal cosmetic procedures. However, 2 years and many new studies later, a systematic review was published in the Menopause journal [15] in which the authors stated that "the FDA safety communication appears unsubstantiated" adding that "The well-documented benefits and low risk of adverse events suggest laser therapy for GSM is reasonable with appropriate pretreatment counseling."

The therapeutic advantages of nonsurgical laser-based devices in urogynecology can only be recommended after robust clinical trials have demonstrated their long-term complication profile, safety, and efficacy. Recently, a global survey about the safety of non-ablative vaginal Erbium laser was published [16], reporting about the safety of this technology used over a period of more than 8 years on more than 113,000 patients in 535 clinics from 43 countries, showing an excellent safety profile of this laser. In the future, we need more robust clinical trials with protocols based on data analysis that has already been carried out. By accurately analyzing already conducted clinical data, this study will be useful for future controlled trials. Moreover, given the international concerns about the artifacts used in the middle sling procedure, it is ethically impossible for vaginal lasers and middle sling procedures to continue in randomized controlled trials. For this reason, PS comparison with past data is very meaningful.

\section{Materials and methods}

\section{Study design}

The present study compared the effects of TVT and VEL on urinary incontinence using retrospective analysis of the
UnIcoRN database, which is a comprehensive database in Japan that we have established to compare VEL to other treatments. Medical records of all registered cases were examined. The TVT group was compared to the VEL group using PS, and the advantages of TVT and VEL were evaluated using odds ratio meta-analysis.

\section{Patients}

SUI was diagnosed based on the International Consultation on Incontinence definition as a "Complaint of involuntary loss of urine on effort or physical exertion (e.g., sporting activities), or on sneezing or coughing" [17] by urological specialists. All identified cases were compared to a control group.

The subjects were patients between 35 and 50 years of age at the time of treatment who (1) underwent TVT surgery, (2) received VEL treatment, or (3) were placed under observation with no treatment (control) for SUI at several facilities, within a period of 15 years between 2004 and 2019. Patients with medical records covering a period of at least 1 year after treatment were registered. The choice of treatment type (VEL or TVT) was up to the patients after the consultations, at which they were informed in detail about both options.

The cost of the laser procedure for this study was the same as the middle sling procedure. For this reason, the price was not a factor on which the patients would choose between the two treatments.

The following selection criteria were applied to the registered patients: (1) availability of medical records before and at 1 year after treatment for the 1-h pad test [18]; (2) completion of the International Consultation on Incontinence Questionnaire-Short Form (ICIQ-SF) [19]; (3) completion of the Overactive Bladder Symptom Score (OABSS) [20]; (4) availability of records from before treatment (including complete information on age; body mass index [BMI] [21-23]; marital status; number of deliveries; desire for children; history of medications for hypertension [23-25], diabetes [24, 25], cerebral infarction [24, 25], and hyperlipidemia [24]); and (5) availability of histories of cerebral infarction, smoking [24, 26], spinal disease, pelvic surgery [26], and menopause [24, 26]. The exclusion criteria were as follows: (1) hospitalization for diseases other than SUI during the 1-year observation period; (2) ongoing female hormone replacement therapy; (3) presence of cystocele, uterine prolapse, or rectocele [20]; and (4) use of overactive bladder (OAB) medications or anticholinergic agents. All patients performed pelvic floor muscle training [PFMT] daily [17].

The UnIcoRN study was launched to document all VEL treatments performed for all types of urinary incontinence (SUI, MUI, and urinary urgency incontinence [UUI]). Sample size was calculated using the Raosoft tool (Raosoft Inc., WA, USA). The sample size for the three groups was 
estimated to provide a $95 \%$ confidence interval with a $5 \%$ margin of error.

We examined 112, 159, and 159 Asian patients who underwent the same treatment protocol for TVT+PFMT, VEL+PFMT, and PFMT alone, respectively. Of these, 102, 113 , and 112 patients without missing data and aged between 35 and 50 years were included in the TVT, VEL, and control groups, respectively. The drop-out rate, i.e., patients who were excluded because of the data missing in their charts, was calculated using Fisher's $F$-test. The $F$-test showed that the differences between TVT vs VEL, VEL vs control, and TVT vs control were $0.27,0.99$, and 0.27 , respectively. There were no statistically significant differences between the three groups.

\section{Treatments and analysis}

TVT surgery [10] was performed by specialists under lumbar anesthesia or general anesthesia using the Advantage Fit ${ }^{\mathrm{TM}}$ Transvaginal Mid-Urethral Sling System (Boston Scientific Co., MA, USA) or the GYNECARE TVT ${ }^{\mathrm{TM}}$ Retropubic System (Ethicon Inc., NJ, USA). The study was conducted for 1 year, with the day of operation being designated as day 0 .

VEL treatment [10] was performed using a standard protocol at all institutions. A non-ablative Erbium:YAG laser (FotonaSmooth ${ }^{\mathrm{TM}} \mathrm{XS}$; Fotona d.o.o., Ljubljana, Slovenia) was used. The vagina was sprayed with $9 \%$ xylocaine, after which a glass speculum made for the laser was inserted into the vagina; the wavelength was set to $2940 \mathrm{~nm}$ and irradiation was performed for $20 \mathrm{~min}$ in a special long-pulse mode. Irradiation was performed first on the entire anterior vaginal wall at $6 \mathrm{~J} / \mathrm{cm}^{2}$ for $10 \mathrm{~min}$, then on the entire vagina at 3.0 $\mathrm{J} / \mathrm{cm}^{2}$ for $5 \mathrm{~min}$, and around the urethra at $10 \mathrm{~J} / \mathrm{cm}^{2}$ for $5 \mathrm{~min}$. Laser irradiation was performed every other month for three treatment sessions [10]. The study was conducted for 1 year, with the day of the first VEL treatment being designated as day 0 .

The surgical procedures for both types of sling as well as the VEL settings and treatment procedures were the same throughout the study period in all centers included in this study.

The daily PFMT [17] was supervised by urology specialists for all patients in the three groups. In the control group, the study was conducted for 1 year, with the day of the first lesson being designated as day 0 .

The primary endpoint was $\leq 1 \mathrm{~g}$ in the 1 -h pad test at 1 year after treatment. This was regarded as a cure for urinary incontinence [3]. The secondary endpoint was improvement in the total ICIQ-SF and OABSS.

Comparisons between the three groups (TVT, VEL, and control) were performed using the Kruskal-Wallis test [11] after the Kolmogorov-Smirnov test. Comparisons between the two groups (TVT, VEL) were performed using the Mann-Whitney $U$ test [11]. Hospital visitation records of the three groups were checked for the number of patients and the results of the 1-h pad test, ICIQ-SF, and OABSS at 0, 3, 6, 9, and 12 months after the first day of treatment. Comparisons between 0 and 12 months were performed using the MannWhitney $U$ test [11]. A $p$ value of $<0.05$ was considered to indicate a significant difference.

For PS estimation [11], we used a logistic regression model in which the treatment status (TVT or VEL) was regressed on the following baseline characteristics: age; BMI; marital status; number of deliveries; menopause status; desire for children; medications for hypertension, diabetes, cerebral infarction, or hyperlipidemia; smoking habits; and a history of spinal disease, breast cancer, or pelvic surgery. BMI $\geq 25 \mathrm{~kg} / \mathrm{m}^{2}$ was considered obese.

Some studies have shown that PS methods result in biased estimates of conditional odds ratios for binary outcomes [27]. We analyzed this study data with multivariate analysis, which can be found in the supplement's figures and tables.

Improvement to $\leq 1 \mathrm{~g}$ in the 1 -h pad test at 1 year after treatment was used in the Peto odds ratio meta-analysis.

The statistical software R version 2.15.1 (R Core Team, Vienna, Austria) and Microsoft Excel version 1911 (Microsoft Corp., WA, USA) on a Windows 10 version 1903 (Microsoft Corp.) operating system were used for all analyses.

\section{Results}

\section{Patient characteristics}

Table 1 summarizes the characteristics of patients in the TVT and VEL groups and focuses on the major differences between patients who chose TVT or VEL in actual clinical practice. A significant difference was only observed for "desire for children" (11.8\% for TVT vs $50.4 \%$ for VEL, $p<0.001$ ) and "number of deliveries" (1.3 for TVT vs 1.1 for VEL, $p=$ 0.015). Between the two treatment groups, women who wanted children selected VEL significantly more often than TVT $(p<0.001)$. The medical records of patients who chose VEL were examined to determine the reasons for this; in all cases, their reason was that they "wanted VEL or to just wait and not have surgery, out of concern the artificial implant from TVT surgery would be a problem in pregnancy and delivery."

\section{Treatment courses}

We focused on the treatment courses of all registered cases. Figure 1a shows the number of patients, and Fig. $1 \mathrm{~b}$ and $\mathrm{c}$ present the results of the 1-h pad test and ICIQ-SF, respectively, both of which significantly improved from 0 to 12 months in the TVT and VEL groups $(p<0.001)$. In the supplement (Fig. 3), we also show the box plot comparison of the TVT 
Table 1 Demographics and populations of the three treatment groups

\begin{tabular}{|c|c|c|c|c|c|}
\hline Parameter & TVT group $(n=102)$ & VEL group $(n=113)$ & Control group $(n=112)$ & $p$ value* & $p$ value $* *$ \\
\hline & & & & (Total) & (TVT vs VEL) \\
\hline Age (years) & $42.5(35-48)$ & $42.7(37-49)$ & $43.3(38-48)$ & 0.275 & 0.417 \\
\hline Body mass index $\left(\mathrm{kg} / \mathrm{m}^{2}\right)$ & $23.2(19-25.5)$ & $22.9(20-25.6)$ & $22.8(20-25.6)$ & 0.366 & 0.178 \\
\hline Married (partner) & $76.5 \%$ & $73.5 \%$ & $75.0 \%$ & 0.878 & 0.612 \\
\hline No. of deliveries & $1.3(0-4)$ & $1.1(0-4)$ & $1.3(0-4)$ & 0.015 & 0.015 \\
\hline Menopause & $11.8 \%$ & $11.5 \%$ & $8.9 \%$ & 0.754 & 0.954 \\
\hline Desire for children & $11.8 \%$ & $50.4 \%$ & $42.9 \%$ & $<0.001$ & $<0.001$ \\
\hline Hypertension & $0.9 \%$ & $1.8 \%$ & $1.8 \%$ & 0.863 & 0.627 \\
\hline Diabetes & $2.0 \%$ & $1.8 \%$ & $3.6 \%$ & 0.635 & 0.922 \\
\hline Cerebral infarction & $1.0 \%$ & $1.8 \%$ & $1.8 \%$ & 0.863 & 0.627 \\
\hline Hyperlipidemia & $2.0 \%$ & $1.8 \%$ & $3.6 \%$ & 0.863 & 0.627 \\
\hline Smoking & $13.7 \%$ & $13.3 \%$ & $13.4 \%$ & 0.995 & 0.925 \\
\hline Spinal disease & $0 \%$ & $0 \%$ & $0 \%$ & 1.0 & 1.0 \\
\hline Breast cancer & $0 \%$ & $0 \%$ & $0 \%$ & 1.0 & 1.0 \\
\hline Pelvic surgery & $\begin{array}{l}2.0 \% \\
2 \text { ovarian cysts }\end{array}$ & $\begin{array}{l}2.7 \% \\
1 \text { ovarian cyst, } 1 \text { uterine cancer, } \\
1 \text { uterine fibroid }\end{array}$ & $\begin{array}{l}1.9 \% \\
1 \text { ovarian cyst, } \\
1 \text { uterine cancer }\end{array}$ & 0.894 & 0.74 \\
\hline 1-h pad test & $31.6 \mathrm{~g}(15-60 \mathrm{~g})$ & $29.9 \mathrm{~g}(14-60 \mathrm{~g})$ & $34.3 \mathrm{~g}(12-62 \mathrm{~g})$ & 0.128 & 0.054 \\
\hline ICIQ-SF & $12.1(8-21)$ & $11.2(7-21)$ & $12.0(8-21)$ & 0.0924 & 0.0612 \\
\hline OABSS & $1.83(0-10)$ & $2.24(0-11)$ & $1.7(0-10)$ & 0.892 & 0.821 \\
\hline
\end{tabular}

Mean, minimum, and maximum values are shown for age, body mass index, number of deliveries, 1-h pad test, ICIQ-SF, and OABSS. Percentages of patients taking medication for hypertension, diabetes, cerebral infarction, and hyperlipidemia are shown. Percentages of patients with a history of pelvic surgery and the names of the main diseases (number of patients) are shown

*The Kruskal-Wallis test was used to compare the three groups (TVT, VEL, and control groups)

**The Mann-Whitney $U$ test was used to compare the two groups (TVT and VEL groups)

group $(n=102)$ and VEL group $(n=113)$ for the 1 -h pad test at 1 year after treatment. Figure $1 \mathrm{~d}$ shows the changes in OABSS. Overactive bladder (OAB) was observed in 39 out of 102 patients in the TVT group and 41 out of 113 patients in the VEL group. While OABSS declined to 0 in 19 patients in the VEL group, this did not occur for any patient in the TVT group, which had two new OAB cases. In the supplement (Fig. 4), we show the change in Q3 and Q4 from "before" to "1 year." There was no significant difference in the TVT group (Q3: $p=0.16$, Q4: $p=0.50)$. In the VEL group, Q3 and Q4 improved significantly (Q3<0.05, Q4 $<0.05)$.

In this study, 34 patients were treated with the Advantage Fit, and 68 patients were treated with the GYNECARE TVT $^{\text {TM }}$ sling. The operation times were $58.0 \pm 10.2$ vs 60.0 $\pm 7.3 \mathrm{~min}(p=0.28)$. Bleeding times were $38.2 \pm 9.0$ vs $36.4 \pm$ $8.7 \mathrm{~min}(p=0.32)$. These data also show that we provided a uniform procedure for all mid-urethral sling patients.

\section{Outcomes}

We compared the TVT and VEL groups with respect to changes in outcomes from pretreatment (0 months) to post-treatment (1 year). Sixty-six pairs were matched using PS. Figure 1e and $\mathrm{f}$ present the results of the 1-h pad test and ICIQ-SF. Both groups exhibited improvements from 0 to 12 months, although the difference between the two therapies was not significant. This indicates that in terms of these two tests, TVT and VEL are equivalent. However, OABSS was significantly different between the VEL and TVT groups ( $p<0.001$; Fig. $1 \mathrm{~g}$ ). OAB was observed in 20 out of 66 patients in the TVT group and 20 out of 66 patients in the VEL group. At 12 months, OAB was noted in 22 out of 66 patients in the TVT group and 13 out of 66 patients in the VEL group. Two patients in the TVT group had both de novo urgency and de novo UUI.

\section{Advantages}

We focused on the advantages of TVT and VEL. Figure 2 divides patients according to whether incontinence was cured or not, with $\leq 1 \mathrm{~g}$ in the $1-\mathrm{h}$ pad test regarded as cured. TVT and VEL had almost the same effect on incontinence. However, the small sample sizes for hypertension, diabetes, cerebral infarction, and hyperlipidemia made it impossible to compare TVT and VEL.

We show the multivariate analysis in the supplement (Tables 2 and 3). 


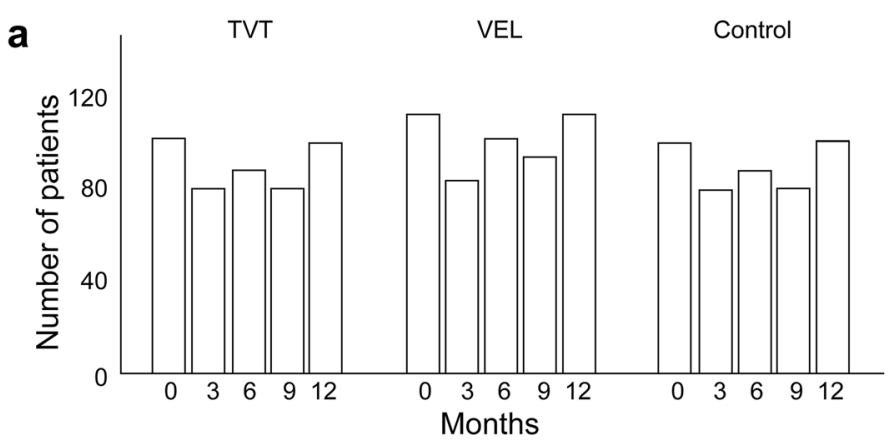

e
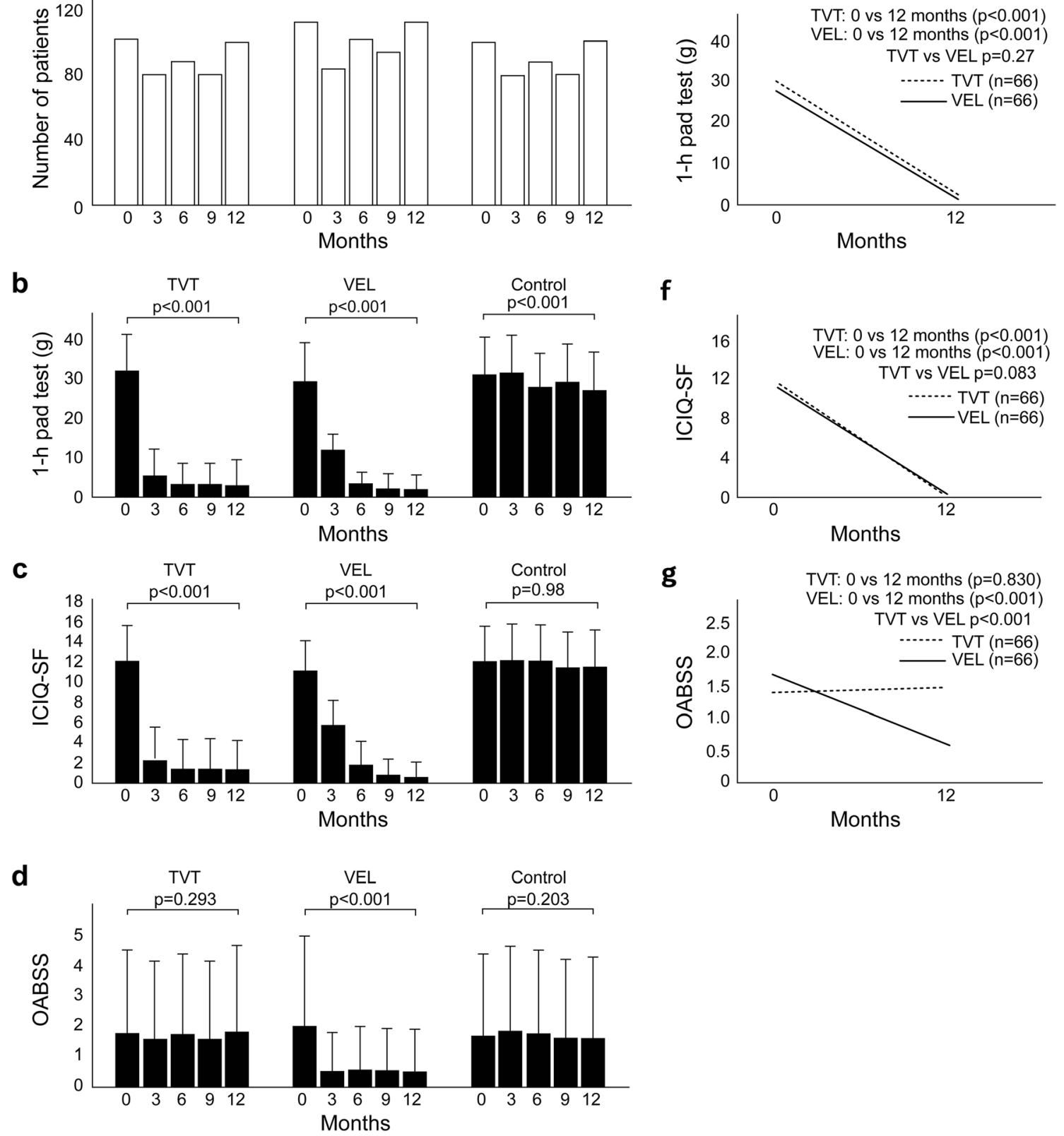

Fig. 1 Treatment in the TVT and VEL groups. a The number of patients at 0 months, 3 months, 6 months, 9 months, and 12 months in three groups. b-d The change over time for the 1-h pad test, ICIQ-SF, and OABSS. There was a significant difference between the start of treatment and 1-year post-treatment in the TVT and VEL groups. No significant

\section{Discussion}

\section{Main findings}

All VEL treatments performed in Japan between 2004 and 2019 were investigated. We compared TVT and VEL as treatments for SUI. In this retrospective study, both methods performed better than controls. Using PS matching, TVT and difference was observed in the control. e- $\mathbf{g}$ Comparison between TVT and VEL with respect to changes in outcomes from pretreatment $(0$ months) to post-treatment (1 year). Only OABSS was significantly different between the two groups. The Mann-Whitney $U$ test was used to compare the three groups at 1 and 12 months post-treatment 
Fig. 2 Advantages of TVT and VEL in Peto odds ratio metaanalysis. Comparison of 1-h pad test from TVT and VEL.

Comparisons were performed between the registered samples, and the samples were statistically processed by PS and the PS subgroups. Patients were divided according to $1-\mathrm{h}$ pad test results, with $\leq 1 \mathrm{~g}$ considered cured, and higher values not cured. TVT was considered superior if the odds ratio was $<1.0$. VEL was considered superior if the odds ratio was larger than 1.0. TVT, tension-free vaginal tape. VEL non-ablative vaginal Erbium:YAG laser treatment, PS propensity score, CI confidence interval

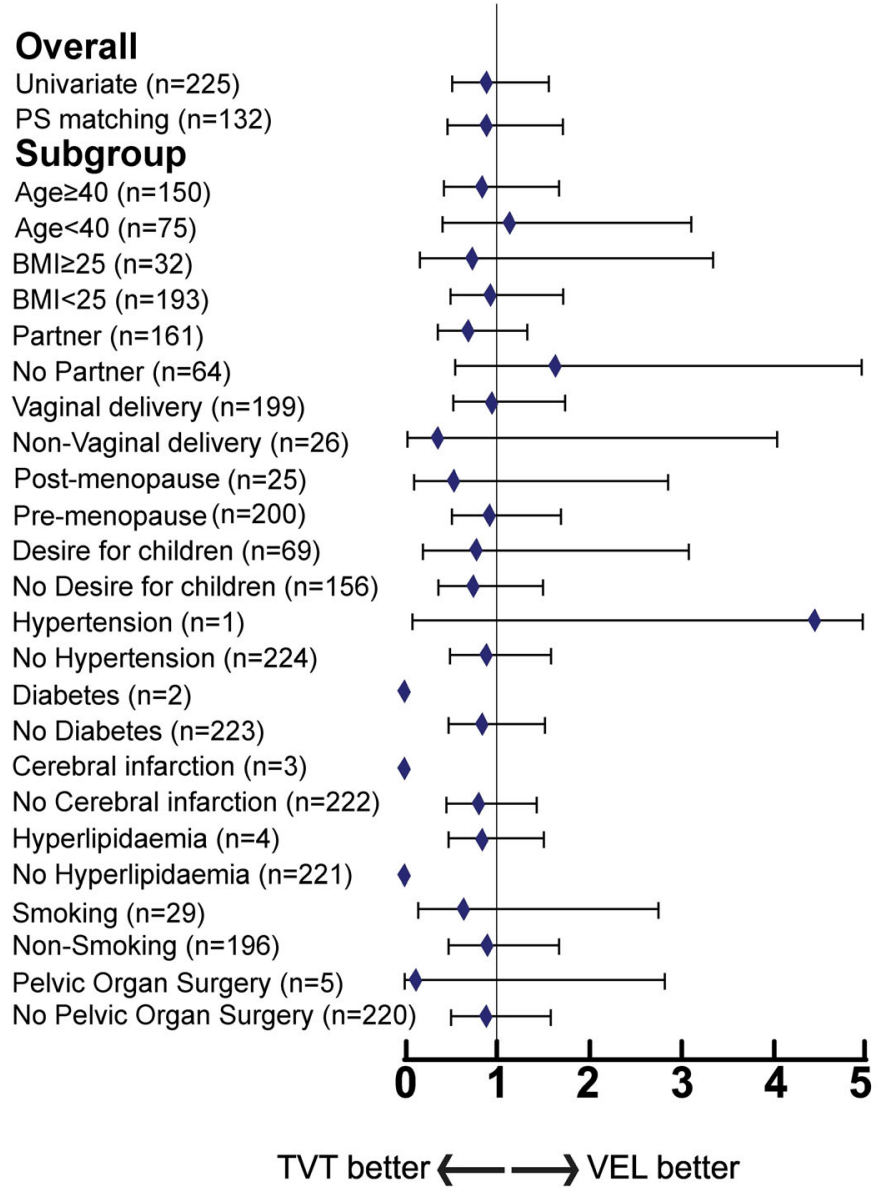

OR $(95 \% \mathrm{Cl})$

$0.89(0.51-1.57)$

$0.89(0.46-1.73)$

$0.85(0.42-1.70)$

$1.15(0.42-3.14)$

$0.74(0.16-3.37)$

$0.93(0.50-1.73)$

$0.69(0.35-1.34)$

$1.65(0.54-5.03)$

$0.96(0.52-1.75)$

$0.36(0.03-4.08)$

$0.55(0.11-2.87)$

$0.93(0.51-1.71)$

$0.79(0.20-3.01)$

$0.75(0.37-1.52)$

$4.48(0.07-286)$

$0.89(0.50-1.59)$

$0.58(0.48-1.52)$

$0.82(0.46-1.73)$

$0.85(0.48-1.52)$

$0.65(0.15-2.77)$

$0.91(0.47-1.70)$

$0.11(0.01-2.84)$

$0.89(0.50-1.60)$

\section{Interpretation}

Based on our current and previous prospective study [10], the VEL and TVT procedures are comparable for SUI; however, laser therapy is superior in terms of MUI. Even after PS matching, de novo UUI and de novo urgency appeared after treatment in the TVT group. With regard to OAB, including UUI and urgency, we saw improvement in the VEL group. In our previous study, we found that some cases of severe MUI worsened with TVT but improved with VEL [10]. The incidence of de novo urgency at 1 year after TVT was reported to be $22.2 \%$ [28]. On the other hand, VEL was not reported to generate de novo urgency or any serious major adverse events [29].

Notably, VEL is inferior to TVT with respect to the time that it took to obtain a cure. A desired effect was observed immediately after surgery with TVT, while this took several months with VEL. This highlights the distinction between using an artificial object in TVT, while VEL involves the proliferation of living cells [30, 31].

To the best of our knowledge, the physiological mechanisms underlying VEL treatment are still unknown [28, 30-32]. The results of our current study indicate that the mechanism of action in VEL differs from that of TVT [32]. We have previously shown that the mechanism of VEL differs from that of $\mathrm{OAB}$ medications and possibly involves improved blood flow in vaginal and bladder tissues [31]. Several studies have shown that pelvic ischemia and oxidative stress may play a main role in lower urinary tract dysfunction (LUTD), including detrusor overactivity (DO)/overactive bladder (OAB) and detrusor underactivity (DU)/underactive bladder (UAB) [33, 34]. At the 2019 International Consultation on Incontinence-Research Society (ICI-RS) meeting [34], this topic was extensively discussed and compared with ischemia of other organs, and the development of pelvic ischemia in animal models [35]. Collagen remodeling from VEL is associated with the induction of revascularization and improved blood flow in tissues [30, 31, 36]. This offers a new field of treatment for managing SUI.

Recently, the important role of blood flow in the urethra and bladder has been noted [37]. Stem cells have been used in treatment of stress urinary incontinence [38]; in a study using adipose-derived regenerative cells, a cytokine release assay showed that adherent cells secreted cytokines associated with angiogenesis, including vascular endothelial growth factor-A, angiopoietin-2, and placental growth factor. Using a stem cell 
therapeutic approach [39] for pelvic floor disorders (PFD), studies using different autologous stem cells have achieved promising results by improving the pelvic ligament and muscle regeneration and conferring tissue elasticity and strength to the damaged tissue in PFD, as well as reducing inflammatory reactions, collagen deposition, and foreign body reaction [39]. However, these studies were not enough to fully evaluate function and side effects. Better quality studies are needed to document the exact mechanism of action, longevity, safety, and its eventual place in the current treatment protocols of SUI and OAB. Artificial urinary sphincter (AUS) in female SUI has been reported for decades, but due to its challenging implantation and inherent morbidity, in most countries it was not in use [40]. Over the past few years, laparoscopic and, more recently, robotic techniques of AUS implantation in female patients have been described with promising perioperative outcomes. The use of AUS in female patients has been restricted to certain countries and a few high-volume centers. PFMT is being studied in combination with electromyography biofeedback (providing visual or auditory feedback of internal muscle movement) [41]. Female patients were positive about both interventions; adherence to the interventions was facilitated by a desire to improve their urinary incontinence and hindered by lack of time. However, one report showed that at 24 months, no evidence was found of any important difference in the severity of urinary incontinence between the PFMT plus electromyographic biofeedback and PFMT only groups [42]. Routine use of electromyographic biofeedback with PFMT should not be recommended. Other ways of maximizing the effects of PFMT should be investigated [42].

Finally, the uncertainty in modern society that surrounds surgical insertion of artificial objects is an important factor [3]. In the present study, we demonstrated how the motivation of patients who had a desire to have children in the future affected their choice of treatment. We focused on the changes in patients who wanted a sexual partner. VEL could represent an alternative option for such patients who are concerned about the artificial implants used in TVT.

\section{Limitations}

This report included a sample population limited to a single ethnicity. There is no published article containing a comparison study of race/ethnicity for incontinence treatment. With pelvic surgical procedures, African American, Hispanic, and Asian/Pacific Islander women eligible for minimally invasive hysterectomy were more likely than white women to receive abdominal hysterectomy [43]. One review shows that extraordinary risk factors such as ethnicity and race, mixed and fecal incontinence, and iatrogenic and neurogenic factors should be discussed in a follow-up report [44]. The results may also be influenced by Asian physical and psychological characteristics.
The physiological mechanism of VEL treatment could not be demonstrated using this study's methodology. In future studies, we need long-term data and more cases [28, 32].

\section{Conclusion}

This study demonstrates that both TVT and VEL are viable options for patients desiring SUI treatment. VEL may be an option for patients with both SUI and OAB symptoms, as TVT can worsen urinary urgency and frequency, and VEL could represent an option for patients who are concerned about artificial implants.

Supplementary Information The online version contains supplementary material available at https://doi.org/10.1007/s10103-021-03317-x.

Acknowledgements We dedicate this research to the memory of our late teacher, Dr. Miyazaki. We also express our gratitude to Ms. Franja Pajk for performing the multivariate analysis.

Availability of data and materials The datasets generated during and/or analyzed during the current study are available in the [Harvard Dataverse] repository, available at https://dataverse.harvard.edu/dataverse/ KAMDP19006.

Code availability $\mathrm{R}$ version 2.15.1 (R Development Core Team, Vienna, Austria), Microsoft Excel version 1911 (Microsoft Corp., WA, USA) on a Windows 10 version 1903 (Microsoft Corp.) operating system, Raosoft tool (Raosoft Inc., WA, USA).

\section{Declarations}

Ethics approval All procedures performed in studies involving human participants were in accordance with the ethical standards of the institutional and/or national research committee and with the 1964 Helsinki Declaration and its later amendments or comparable ethical standards. The study protocol was approved by the Ethical Review Board of the Kanagawa Association of Medical and Dental Practitioners (19006), complying with Japanese law. Opt-outs were solicited in 2019 via a joint website (http://unicorn-study.net/) for patients. The Urinary Incontinence Research Network (UnIcoRN) database is registered at the University Hospital Medical Information Network (UMIN) Center (R00004294).

Consent to participate Written informed consent was obtained from all individual participants included in the study. Opt-outs were solicited in 2019 via a joint website (http://unicorn-study.net/) for patients.

Consent for publication The participants have consented to the submission of the case report to the journal with a consent form document.

Open Access This article is licensed under a Creative Commons Attribution 4.0 International License, which permits use, sharing, adaptation, distribution and reproduction in any medium or format, as long as you give appropriate credit to the original author(s) and the source, provide a link to the Creative Commons licence, and indicate if changes were made. The images or other third party material in this article are included in the article's Creative Commons licence, unless indicated otherwise in a credit line to the material. If material is not included in the article's 
Creative Commons licence and your intended use is not permitted by statutory regulation or exceeds the permitted use, you will need to obtain permission directly from the copyright holder. To view a copy of this licence, visit http://creativecommons.org/licenses/by/4.0/.

\section{References}

1. Abrams P, Cardozo L, Fall M, Griffiths D, Rosier P, Ulmsten U, Van Kerrebroeck P, Victor A, Wein A, Standardisation SubCommittee of the International Continence Society (2002) The standardisation of terminology of lower urinary tract function: Report from the Standardisation Sub-committee of the International Continence Society. Neurourol Urodyn 21:167-178. https://doi.org/10.1002/nau.10052

2. Hunskaar S, Burgio K, Diokno A, Herzog AR, Hjälmås K, Lapitan MC (2003) Epidemiology and natural history of urinary incontinence in women. Urology 62(Suppl 4A):16-23

3. Heneghan C, Aronson JK, Goldacre B, Mahtani KR, Plüddemann A, Onakpoya I (2017) Transvaginal mesh failure: Lessons for regulation of implantable devices. BMJ 359:j5515

4. Franić D, Fistonić I (2019) Laser therapy in the treatment of female urinary incontinence and genitourinary syndrome of menopause: An update. Biomed Res Int 2019:1576359. https://doi.org/10. 1155/2019/1576359

5. Vizintin Z, Lukac M, Kazic M, Tettamanti M (2015) Erbium laser in gynecology. Climacteric 18:4-8. https://doi.org/10.3109/ 13697137.2015.1078668

6. Mitsuyuki M, Štok U, Hreljac I, Yoda K, Vižintin Z (2020) Treating vaginal laxity using nonablative Er:YAG laser: A retrospective case series of patients from 2.5 years of clinical practice. Sex Med 8:265-273. https://doi.org/10.1016/j.esxm.2020.01.001

7. Dams SD, de Liefde-van Beest M, Nuijs AM, Oomens CW, Baaijens FP (2010) Pulsed heat shocks enhance procollagen type I and procollagen type III expression in human dermal fibroblasts. Skin Res Technol 16:354-364. https://doi.org/10.1111/j.16000846.2010.00441.x

8. Tien YW, Hsiao SM, Lee CN, Lin HH (2017) Effects of laser procedure for female urodynamic stress incontinence on pad weight, urodynamics, and sexual function. Int Urogynecol J 28: 469-476. https://doi.org/10.1007/s00192-016-3129-y

9. Lin YH, Hsieh WC, Huang L, Liang CC (2017) Effect of nonablative laser treatment on overactive bladder symptoms, urinary incontinence and sexual function in women with urodynamic stress incontinence. Taiwan J Obstet Gynecol 56:815-820. https://doi. org/10.1016/j.tjog.2017.10.020

10. Okui N (2019) Comparison between erbium-doped yttrium aluminum garnet laser therapy and sling procedures in the treatment of stress and mixed urinary incontinence. World J Urol 37:885-889. https://doi.org/10.1007/s00345-018-2445-x

11. Hara M, Sakata $Y$, Nakatani D, Suna S, Usami M, Matsumoto S, Sugitani T, Nishino M, Sato H, Kitamura T, Nanto S, Hamasaki T, Hori M, Komuro I, OACIS Investigators (2014) Comparison of 5year survival after acute myocardial infarction using angiotensinconverting enzyme inhibitor versus angiotensin II receptor blocker. Am J Cardiol 114:1-8. https://doi.org/10.1016/j.amjcard.2014.03. 055

12. Phillips C, Hillard T, Salvatore S, Toozs-Hobson P, Cardozo L (2020 Aug) Lasers in gynaecology. Eur J Obstet Gynecol Reprod Biol 251:146-155. https://doi.org/10.1016/j.ejogrb.2020.03.034.)

13. Shobeiri SA, Kerkhof MH, Minassian VA, Bazi T, IUGA Research and Development Committee (2019) IUGA committee opinion: Laser-based vaginal devices for treatment of stress urinary incontinence, genitourinary syndrome of menopause, and vaginal laxity.
Int Urogynecol J 30(3):371-376. https://doi.org/10.1007/s00192018-3830-0

14. Robinson D, Flint R, Veit-Rubin N, Araklitis G, Cardozo L (2020) Is there enough evidence to justify the use of laser and other thermal therapies in female lower urinary tract dysfunction? Report from the ICI-RS 2019. Neurourol Urodyn 39(Suppl 3):S140-S147. https:// doi.org/10.1002/nau.24298

15. Guo JZ, Souders C, McClelland L, Anger JT, Scott VCS, Eilber KS, Ackerman AL (2020) Vaginal laser treatment of genitourinary syndrome of menopause: Does the evidence support the FDA safety communication? Menopause 27(10):1177-1184. https://doi.org/10. 1097/GME.0000000000001577

16. Gambacciani M, Cervigni M, Gaspar A, Novakov Mikić A, Gaviria J, Koron N, Vizintin Z (2020) Safety of vaginal erbium laser: A review of 113,000 patients treated in the past 8 years. Climacteric 23(sup1):S28-S32. https://doi.org/10.1080/13697137.2020. 1813098

17. Haylen BT, de Ridder D, Freeman RM, Swift SE, Berghmans B, Lee J, Monga A, Petri E, Rizk DE, Sand PK, Schaer GN, International Urogynecological Association; International Continence Society (2010) An International Urogynecological Association (IUGA)/International Continence Society (ICS) joint report on the terminology for female pelvic floor dysfunction. Neurourol Urodyn 29:4-20. https://doi.org/10.1002/nau.20798

18. Abdel-fattah M, Barrington JW, Youssef M (2004) The standard 1hour pad test: Does it have any value in clinical practice? Eur Urol 46:377-380. https://doi.org/10.1016/j.eururo.2004.04.018

19. Takahashi S, Takei M, Nishizawa O, Yamaguchi O, Kato K, Gotoh M, Yoshimura Y, Takeyama M, Hideo O, Shimada M, Yamanishi T, Yoshida M, Tomoe H, Yokoyama O, Koyama M (2013) Clinical guidelines for female lower urinary tract symptoms. The Neurogenic Bladder Society, Tokyo, pp 6-168

20. Sako T, Inoue M, Watanabe T, Ishii A, Yokoyama T, Kumon H (2011) Impact of overactive bladder and lower urinary tract symptoms on sexual health in Japanese women. Int Urogynecol J 22: 165-169. https://doi.org/10.1007/s00192-010-1250-x

21. Huffaker RK, Livers N, Yandell PM, Shull BL, Muir TW, Kuehl TJ, Bird ET (2010) Does body mass index impact passing voiding trial after midurethral sling procedures for stress urinary incontinence? Female Pelvic Med Reconstr Surg 16:358-361. https:// doi.org/10.1097/SPV.0b013e3181ff394e

22. Fistonić I, Fistonić N (2018) Baseline ICIQ-UI score, body mass index, age, average birth weight, and perineometry duration as promising predictors of the short-term efficacy of Er:YAG laser treatment in stress urinary incontinent women: A prospective cohort study. Lasers Surg Med. https://doi.org/10.1002/lsm.22789 Online ahead of print

23. Tsui A, Kuh D, Cardozo L, Davis D (2018) Vascular risk factors for male and female urgency urinary incontinence at age 68 years from a British birth cohort study. BJU Int 122:118-125. https://doi.org/ 10.1111/bju.14137

24. Kokanali MK, Doğanay M, Aksakal O, Cavkaytar S, Topçu HO, Özer İ (2014) Risk factors for mesh erosion after vaginal sling procedures for urinary incontinence. Eur J Obstet Gynecol Reprod Biol 177:146-150. https://doi.org/10.1016/j.ejogrb.2014.03.039

25. Tamer EC, Inan D, Mut A (2020) Predictive factors for the efficacy of Er:YAG laser treatment of urinary incontinence. Maturitas 132: 1-6. https://doi.org/10.1016/j.maturitas.2019.11.003

26. Chang KM, Hsieh CH, Chiang HS, Lee TS (2014) Risk factors for urinary incontinence among women aged 60 or over with hypertension in Taiwan. Taiwan J Obstet Gynecol 53:183-186. https://doi. org/10.1016/j.tjog.2014.04.010

27. Austin PC (2018) Assessing the performance of the generalized propensity score for estimating the effect of quantitative or continuous exposures on binary outcomes. Stat Med 37:1874-1894. https://doi.org/10.1002/sim.7615 
28. Lleberia-Juanós J, Bataller-Sánchez E, Pubill-Soler J, Mestre-Costa M, Ribot-Luna L, Vizcaíno MA (2011) De novo urgency after tension-free vaginal tape versus transobturator tape procedure for stress urinary incontinence. Eur J Obstet Gynecol Reprod Biol 155: 229-232. https://doi.org/10.1016/j.ejogrb.2010.12.026

29. Mackova K, Van Daele L, Geraerts I, Krofta L, Deprest J (2020) Laser therapy for urinary incontinence and pelvic organ prolapse: A systematic review. BJOG. https://doi.org/10.1111/1471-0528. 16273

30. Gambacciani M, Palacios S (2017) Laser therapy for the restoration of vaginal function. Maturitas 99:10-15. https://doi.org/10.1016/j. maturitas.2017.01.012

31. Okui N (2019) Efficacy and safety of non-ablative vaginal erbium: YAG laser treatment as a novel surgical treatment for overactive bladder syndrome: Comparison with anticholinergics and $\beta 3-$ adrenoceptor agonists. World J Urol 37:2459-2466. https://doi. org/10.1007/s00345-019-02644-7

32. Kuszka A, Gamper M, Walser C, Kociszewski J, Viereck V (2019) Erbium:YAG laser treatment of female stress urinary incontinence: Midterm data. Int Urogynecol J 11:1-8. https://doi.org/10.1007/ s00192-019-04148-9

33. Tamer EC, Fernandez LDC, Inan D, Makul M (2020) Er:YAG laser treatment of urinary incontinence after failed tot/tvt procedures. Eur J Obstet Gynecol Reprod Biol. https://doi.org/10.1016/j.ejogrb. 2020.07.010

34. Andersson KE, Boedtkjer DB, Forman A (2016) The link between vascular dysfunction, bladder ischemia, and aging bladder dysfunction. Ther Adv Urol 9:11-27. https://doi.org/10.1177/ 1756287216675778

35. Speich JE, Tarcan T, Hashitani H, Vahabi B, McCloskey KD, Andersson KE, Wein AJ, Birder LA (2020) Are oxidative stress and ischemia significant causes of bladder damage leading to lower urinary tract dysfunction? Report from the ICI-RS 2019. Neurourol Urodyn 39 Suppl 3:S16-S22. https://doi.org/10.1002/nau.24313

36. Gaspar A, Silva J, Calderon A, Di Placido V, Vizintin Z (2020) Histological findings after non-ablative Er:YAG laser therapy in women with severe vaginal atrophy. Climacteric 23(sup1):S11S13. https://doi.org/10.1080/13697137.2020.1764525

37. Penteado CF, Priolli DG, Priviero FBM, Claudino MA, FrancoPenteado CF, Priolli DG, Priviero FBM, Claudino MA (2019) Progression of micturition dysfunction associated with the development of heart failure in rats: Model of overactive bladder. Life Sci 226:107-116. https://doi.org/10.1016/j.lfs.2019.04.017
38. Okabe YT, Shimizu S, Suetake Y, Matsui-Hirai H, Hasegawa S, Takanari K, Toriyama K, Kamei Y, Yamamoto T, Mizuno M, Gotoh M (2020) Biological characterization of adipose-derived regenerative cells used for the treatment of stress urinary incontinence. Int J Urol 28:115-124. https://doi.org/10.1111/iju.14408 Online ahead of print

39. Cheng J, Zhao ZW, Wen JR, Wang L, Huang LW, Yang YL, Zhao FN, Xiao JY, Fang F, Wu J, Miao YL (2020) Status, challenges, and future prospects of stem cell therapy in pelvic floor disorders. World J Clin Cases 8:1400-1413. https://doi.org/10.12998/wjcc. v8.i8.1400

40. Peyronnet B, Greenwell T, Gray G, Khavari R, Thiruchelvam N, Capon G, Ockrim J, Lopez-Fando L, Gilleran J, Fournier G, Van Koeveringe GA, Van Der Aa F (2020) Current use of the artificial urinary sphincter in adult females. Curr Urol Rep 21:53. https://doi. org/10.1007/s11934-020-01001-1

41. Hagen S, Bugge C, Dean SG, Elders A, Hay-Smith J, Kilonzo M, McClurg D, Abdel-Fattah M, Agur W, Andreis F, Booth J, Dimitrova M, Gillespie N, Glazener C, Grant A, Guerrero KL, Henderson L, Kovandzic M, McDonald A, Norrie J, Sergenson N, Stratton S, Taylor A, Williams LR (2020) Basic versus biofeedback-mediated intensive pelvic floor muscle training for women with urinary incontinence: The OPAL RCT. Health Technol Assess 24:1-144. https://doi.org/10.3310/hta24700

42. Hagen S, Elders A, Stratton S, Sergenson N, Bugge C, Dean S, Hay-Smith J, Kilonzo M, Dimitrova M, Abdel-Fattah M, Agur W, Booth J, Glazener C, Guerrero K, McDonald A, Norrie J, Williams LR, McClurg D (2020) Effectiveness of pelvic floor muscle training with and without electromyographic biofeedback for urinary incontinence in women: Multicentre randomised controlled trial. BMJ 371:m3719. https://doi.org/10.1136/bmj.m3719

43. Pollack LM, Olsen MA, Gehlert SJ, Chang SH, Lowder JL (2020) Racial/ethnic disparities/differences in hysterectomy route in women likely eligible for minimally invasive surgery. J Minim Invasive Gynecol 27:1167-1177.e2. https://doi.org/10.1016/j.jmig.2019.09. 003

44. Newman DK, Cardozo L, Sievert KD (2013) Preventing urinary incontinence in women. Curr Opin Obstet Gynecol 25:388-394. https://doi.org/10.1097/GCO.0b013e328364a35d

Publisher's note Springer Nature remains neutral with regard to jurisdictional claims in published maps and institutional affiliations. 